\title{
Erratum: Willenbacher, E., et al. Curcumin: New Insights into an Ancient Ingredient against Cancer. Int. J. Mol. Sci. 2019, 20, 1808
}

Ella Willenbacher ${ }^{1}$, Shah Zeb Khan ${ }^{2}$ D, Sara Cecilia Altuna Mujica ${ }^{3}$, Dario Trapani ${ }^{4}$, Sadaqat Hussain ${ }^{5}$, Dominik Wolf ${ }^{1}$, Wolfgang Willenbacher ${ }^{1,6}$, Gilbert Spizzo ${ }^{1,7}$ and Andreas Seeber 1,*(i)

1 Department of Internal Medicine V: Hematology and Oncology, Medical University of Innsbruck, 6020 Innsbruck, Austria; ella.willenbacher@i-med.ac.at (E.W.); dominik.wolf@i-med.ac.at (D.W.); wolfgang.willenbacher@tirol-kliniken.at (W.W.); gilbert.spizzo@i-med.ac.at (G.S.)

2 Department of Clinical Oncology, BINOR Cancer Hospital, Bannu 28100, Pakistan; skhanizhere0@gmail.com 3 Department of Molecular Biology, Laboratorio Blau, Caracas 1071, Venezuela; altunamujica.md@gmail.com

4 Department of Oncology and Hematology, University of Milan, IEO, European Institute of Oncology IRCCS, 20122 Milan, Italy; dario.trapani@ieo.it

5 Medical Oncology Department, KAMC NGHA, Riyadh 14413, Saudi Arabia; oncologysh@gmail.com

6 Oncotyrol, Center for Personalized Cancer Therapy, 6020 Innsbruck, Austria

7 Oncologic Day Hospital, 39042 Bressanone, Italy

* Correspondence: andreas.seeber@tirol-kliniken.at; Tel.: +0043-50504-23001

Received: 26 June 2020; Accepted: 29 June 2020; Published: 10 August 2020

We would like to change the authors' names and affiliations on Page 1 of paper [1] from:

${ }^{4}$ Department of Oncology and Hematology, University of Milan, European Institute of Oncology, 20122 Milan, Italy; dario.trapani@ieo.it

to the correct version, as follows:

${ }^{4}$ Department of Oncology and Hematology, University of Milan, IEO, European Institute of Oncology IRCCS, 20122 Milan, Italy; dario.trapani@ieo.it

We apologize for any inconvenience caused to the readers.

\section{Reference}

1. Willenbacher, E.; Khan, S.Z.; Mujica, S.C.A.; Trapani, D.; Hussain, S.; Wolf, D.; Willenbacher, W.; Spizzo, G.; Seeber, A. Curcumin: New Insights into an Ancient Ingredient against Cancer. Int. J. Mol. Sci. 2019, 20, 1808. [CrossRef] [PubMed]

(C) 2020 by the authors. Licensee MDPI, Basel, Switzerland. This article is an open access article distributed under the terms and conditions of the Creative Commons Attribution (CC BY) license (http://creativecommons.org/licenses/by/4.0/). 